\title{
Culture and Theory: Considerations for the Ethnic Restaurant and Food Safety Culture
}

\author{
By Kimberly J. Harris ${ }^{*}$
}

This study examined the culture associated with the ethnic restaurant and the challenges the small, independent ethnic operator faces with regard to food safety. It is well documented that ethnic restaurants have significantly high number of critical violations compared to non-ethnic restaurants in the United States. While this information is public and appears in academic research as a growing issue, researchers have yet to identify why this occurs and what the needs of the ethnic operator might have in comparison to the non-ethnic operator. Authentic ethnic restaurants are predominantly non-chains, individually-operated, staffed with family members or others of their ethnic group, and are culturally authentic. According to Jang et al. (2011), the ethnic food market was predicted to grow 50 percent higher from the reported $\$ 75$ billion in sales in 2005 to a total of $\$ 112.5$ billion in 2015. The ethnic restaurant is considered part of the American dining experience and therefore, it is pertinent to investigate the unique needs of this restaurant segment.

Keywords: food safety, culture, ethnic restaurant, sanitation, training.

\section{Introduction}

It has been suggested that the authentic ethnic restaurants has inadequate food safety training, lack of proper equipment, low language skills, and an unclear understanding of the expectations of governing bodies requiring food safety compliance are some of the culprits causing high numbers of critical violations cited by food safety inspectors (Cho et al., 2013; Quested et al, 2010). Studies also suggest that the current inspection methods do not address specifics of authentic ethnic preparation techniques involved nor the cultural beliefs in food handling (Roberts et al., 2011; Kang et al., 2015). It is further suggested that the inconsistency with food safety inspection implementation and the variability of state programs to use differing inspection forms, may also pose bias as to the violations cited. While states and counties therein may design their own forms and determine the frequency in which they will inspect, all inspection programs must meet FDA requirements and most recently, may choose to inspect with a frequency contingent on a risk-based program.

Included in this investigation is an overview of the cultural differences of several ethnic populations with regard to food preparation techniques and approaches to food handling. To educate the public as to the uniqueness of food products prepared by techniques passed down through generations of people is part of what Peterson (2004) describes as Cultural Intelligence, and should be considered when changes due to safe food handling techniques may

\footnotetext{
* Professor, Dedman School of Hospitality, Florida State University, USA.
} 
ultimately change the uniqueness of the food product. It should be noted that, despite the food safety violations cited during inspections by food safety inspectors, the number of foodborne illness outbreaks associated with some of the highest number of cited violations, especially among ethnic restaurants, have not resulted in foodborne illness outbreaks (Harris et al, 2015). Therefore, the importance of this study is to highlight the important details of food safety among the ethnic restaurant that must be addressed while protecting the important cultural food handling techniques that present no harm to the public, but maintain the cultural expressions of food that are not only desired by the public, but maintain the cultural identity of foods that are not only tourism and destination travel determinants, but important to maintaining the diversity of populations that continue to intrigue and drive the traveling public.

Segments of this study include the Theory of Cultural Intelligence, challenges faced by ethnic restaurant operators who are committed to their culture's food preparation techniques, but are challenged to change the method in which certain foods unique to their menu items due to enforced food safety guidelines. The question of the true threat to the public and identification of "hazard" is presented, training that should be implemented for food production staff, Drivers of Success in protecting the cultural identity of the ethnic restaurant, and suggestions made for the ethnic operator that will not only satisfy the food safety compliance demands, but maintain cultural identity when offering unique products to the public.

\section{Cultural Intelligence}

Brooks Peterson (2004) presents the Theory of Cultural Intelligence through scales that identify the likelihood of developing communication and partnerships with those of differing cultures. The attributes of culture, as presented, include equality/hierarchy, direct and indirect communication, individuals/group, task/relationship, and risk/caution. In this theory of Five Basic Cultural Scales (FBCS), the author presents culture as integral in the way individuals believe they are accepted or not. Those of a subordinate culture behave on a scale according to the presentation of the dominant culture. This theory suggests that interaction depends on whether individuals of the subordinate culture perceive that they are equal to the dominant culture, effectively communicating with the dominant culture, perceived as an individual or a representation of their cultural group by the dominant culture, given meaningful tasks by the dominant culture, and based on the scale outcome of the mentioned attributes, willing to risk acceptance by the dominant culture. There is, with many Eastern cultures, the attributes of honor and shame, which influences the interaction with Western cultures. Some Eastern cultures, such as Chinese and Korean cultures, are aware and protective of social order and cultural behaviors despite rules and regulations of Western cultures (Yoo, 2015; Liu \& Kwon, 2013). Bennett (1986) suggests 
that similar attributes in the Theory of Cultural Intelligence are similar to the model introduced in the Model of Intercultural Sensitivity, discussed in the next segment of this paper, as being crucial to cultural integration of all people. To overlook the impact of culture on the behaviors of those trying to integrate is considered, in the model, to be a major barrier and, ethically inconsiderate.

The Korean consumer has been reported to show an increasingly high demand for information about the safety of the food consumed, access to educational materials, and methods that can be practiced at home and work to improve safe food handling; however, despite the Support of Diet Education Act (2009) that was aimed at improving education and outreach to consumers along with the Special Act on the Safety Management of Children's Dietary Life enacted that same year, little change has resulted in the food handling methods in the home. The unsafe food handling has therefore been attributed to culture, habit, family expectation of food preparation and the protection of heritage that over-rides recommended procedures (Kang et al., 2015). Liu and Kwon (2013) report similar results in their study of Chinese values, attitudes, and behaviors toward food safety training. They reported that lack of money, labor/energy, and perceived need were all reasons posed as barriers to handling food safety, despite the known need to improve safe food handling practices. Similarly, Latino, Italian, and Slovak cultures have similar cultural beliefs toward food safety. Food is an integral part of socializing, identification, family togetherness, and a feeling of group belonging (Fabiano, 2014; Jevsnik, 2008; Ram et al.; 2000). Fabiano (2014) suggests that food preserves a culture and recipes that are passed down through generations keeps a culture alive, educates others, and often relates to religious faiths. Food is used in virtually all social celebrations, travels, funerals, religious rituals, holidays, events and intimate family meals. Culturally, food is used to communicate when language barriers exist.

There are certain violations that ethnic restaurants are known for committing. Poor personal hygiene, lack of temperature control in heating, cooling, and re-heating and contaminated equipment are hazards well documented in the literature. It is also repeated reported that many food handling behaviors that put food at risk are those that start in the home (ByrdBredbenner et al., 2013; Yoo, 2015 Kang, 2015; Liu \& Kwon, 2013; Powell et al., 2011). Kang et al (2015) reported that in the Korean culture, safe food handling in the home is not considered to be a risky environment for food safety. Kang's study further reported that this culture's food preparation techniques require more food handling than do most other cultures. Culture is often overlooked as an underlying factor in the way employees behave, despite organizational and social expectations. Protective of history, family, and reputation among peers are three reasons cited by researchers of intercultural sensitivity as being powerful indicators of ethnocentrism to ethnorelativism, a developmental scale presented as a process in which people integrating into an culture that is different from their own, grow through progressively as they adapt to difference. Bennett (1986) presents a model of intercultural sensitivity that explains the failure of organizations to supply training and general work 
environments that consider the subordinate culture and how this lack of sensitivity degrades the overall effectiveness of the organization to succeed. The model presents a scale of development in which an employee is in an ethnocentric, or see a culture presented in comparison to one's dominant culture, as the entry-level perspective of an individual to an organization. As this individual reaches ethnorelativity, or successful integration into the presented culture, the individual experiences levels of denial, defensiveness, minimization, acceptance, adaptation, and finally, integration (Parsa et al., 2015; Pfeffer, 1998). The differences posed by culture integration often get ignored when the ethnic operator is required to adopt and immediately perform food safety compliance required of state agencies enforcing code. For the ethnic restaurant to be successful in embracing a food safety culture, it must be more than offering written and verbal appropriate training and adequate tools; it is about leadership and a commitment to quality (Medeiros et al., 2012).

\section{Accommodating the Ethnic Operator and Employee}

Based on the literature, the authentic ethnic restaurant operator and their employees are at a disadvantage when it comes to food safety and the regulations imposed in the United States (Abidin et al., 2013; Cho, et al., 2013; Liu \& Kwon, 2013). The tendency to handle food differently, use unique equipment, and practice food handling procedures that are culturally accurate, yet not always following food handling guidelines, are challenges to food safety compliance in the United States. There needs have been outlined as the following:

1. Training written and portrayed culturally accurate, using verbiage familiar with the employee

2. Evaluations from state food safety inspection agencies that consider the unique food handling, preparation, and service of ethnic food

3. Sensitivity to the communication styles of different cultures calls for both written and verbalized expectations must be considered

4. Supervisors that are of the same culture as the majority of the ethnicity of the employees

5. Expectations for employees to abide by the rule and regulations of management

6. Strict policies for non-compliance; high rewards for employee buy-in of set goals

7. Support for education and employee assistance programs

8. Developing a food safety culture within the organization that meets state food safety expectations

9. Employee recognition programs for meeting expected performance goals

10. Leadership that is values-driven leadership; reinforced, encouraged, and open to offering an environment of continuous learning 
The above list is a compilation of suggestions from the academic literature. Contributors committed to the ethnic and cultural challenges of what Leonard Berry refers to as the Drivers of Sustainable Success, in the text, Discovering the Soul of Service (1999). This text outlines the leadership that is valuesdriven, targeted at underserved markets, a segment of business of which the ethnic operator identifies. The drivers are suggested for leaders to abide by as they conduct business, hire employees, and compete in the market. This book divulges the attributes of success-sustaining companies that have nine strategies on which their companies are based. These drivers of success include 1) Leading with Values, 2) Strategic Focus, 3) Executional Excellence, 4) Control of Destiny, 5) Trust-Based Relationships, 6) Investment in Employee Success, 7) Acting Small, 8) Brand Cultivation, and 9) Generosity. Each of these attributes guide business leadership and the 'soul' of serving others while ultimately serving the goals of the organization. For the ethnic operator, these drivers are presented as considerations for improving food safety compliance in cultivating a culture of excellence, hiring employees with a willingness to learn and respect the rules of serving safe food, and building an environment of trust, which for the subordinate cultures featured in this investigation, is a noted attribute that fosters group and individual cooperation. Khoury (2006) mentions similar scale references and expands to offer a perspective on several of the Drivers of Success for the ethnic restaurant operator.

\section{Drivers of Success for the Ethnic Restaurant}

The academic literature on ethnic restaurant operations have revealed that the ethnic operator is unique. There are both overt and covert management techniques, food handling procedures, employee management styles, and a tendency for the ethnic restaurant to be staffed with family members. Usually small, limited menu, and tucked in out-of-the way places are usual descriptors for the authentic ethnic establishment and depending on the depth of authenticity, patronage becomes more ethnic-authentic. A common saying in the United States when searching for such authenticity is to "ask a local where the locals go" (Leffel, 2016), directives of which leads consumers searching for a true ethnic food dining experience. While this experience may be unique; the drivers of success for such small operations to stay in business depend upon key factors.

The key factors, or drivers, of success of the small, independent, ethnic operator are five-fold:

First, stay true to the culture represented. This driver is interpreted through décor, music, service style, menu offerings, and production techniques. Consumers make restaurant selections long before they enter the restaurant and for some, it is initially through the recommendations of others, but once arriving on or near the property, consumers begin to made decisions that can be hedonic, utilitarian, or economic (Ruiz et al, 2010). Hedonic influences are those such as pleasure derived from sensory stimulation. Sights, sounds, touch, 
and smells that are internal and external are those that influence final decisions on whether or not to make a purchase. Therefore, to the consumer who has decided to dine at a particular establishment, the approach to the restaurant (parking lot, lighting outside, landscaping, cleanliness of the entrance, and a well maintained building are examples) as well as the senses that are stimulated once inside can begin the authentic experience or detract from it. Once inside, consumers are inundated with smells that can be from the food being prepared, plants, incense, or foliage and plants. While the expectation of smell and sigh should always communicate cleanliness; the sights and smells of an authentic restaurant communicating non-verbally its ethnic background can significantly influence perception, anticipation of an experience, and ultimately, dining behavior (Harris et al, 2015).

Second, train staff to be professionals and have staff that are professionally trained. This driver is true for all restaurants, but proves to be especially true for the non-chain, locally owned and operated, often familystaffed operation. Staff that are knowledgeable of the products, deliver a service style that is consistent and efficient, and communicate verbally in both the language of the ethnicity represented and the language of the location in which the restaurant resides, are basic expectations of the dining public. According to Abidin et al (2013), consumers are becoming increasingly savvy with regard to safe food handling techniques, knowledgeable about products in food (especially allergens), and time food has been exposed. Diners may not test food products for temperature nor assess the possible length of time food has been exposed to dangerous conditions; however, they know if food is to be served cold or hot and whether it looks fresh. The physical appearance of staff also communicates their dedication to cleanliness as well as the possible cleanliness adhered to in the back of the house, so having staff that present a high level of personal hygiene, clean uniforms that are ironed and free of stains and shoes that are polished communicates an employee policy that cares about sanitation and goes so far as to require staff to be well-groomed. Requiring both back-of-the-house $(\mathrm{BOH})$ and front-of-the-house $(\mathrm{FOH})$ staff to $\mathrm{BOH}$ to possess food handling certificates and encouraging staff to further their education is a sub-set driver that will impact the overall professionalism of the restaurant.

Third, keep accurate financial records. The small operator is often managed by one person who is responsible for procurement of product, hiring and training of staff, maintaining the facility, preparing food, serving customers, and managing the financial performance of the restaurant. Overwhelming tasks often lead to complacency; however, the importance of this third driver, keeping accurate and up-to-date financial records, cannot be over-emphasized (Ram et al, 2013). Often without the funds to retain professional support for accounting assistance, the small business ethnic operator is left to tally the debits and credits of each day, enter this information into an accounting system, and log the data for tax reporting. Keeping clear, easy to read, detailed information lends a greater level of control for small business operations and allows forecasting to predict future costs and sales. 
Training an additional person, often a family member, to assist with this procedure is a contingency plan, person to double-check records, and possibly plan for future growth is worth considering.

Fourth, cost all menu items and apply one of the myriad of menu pricing methods. The restaurant business depends on the sale of food and beverage items. It is no different than selling cars, groceries, or nuts and bolts; therefore, a restauranteur must consider every ingredient, including costly spices, as currency. Lack of portion control, accurate measurement of ingredients, food orders that are incorrect, and food that is refused by customers when served are all examples of lost revenue. The fourth driver, menu pricing, means that everything on the menu has been costed and found to be revenue generating, either as an a la carte item or combined with other products (calculated as "plate cost") so that the restaurateur can calculate but tallying the register ticket at the end of a shift or day, a very close approximate of costs and sales data. In the book by Kenneth Blanchard titled, "Raving Fans" (1993), the author explains that a successful business must know the most minute details, be obsessed with tracking every nut, package of salt, and straw to truly be in control of one's destiny. He further recommends that an entrepreneur understand the entire service scape, and not just individual sales encounters. In the context of operating restaurants, his advice in the journey of being successful is to keep options open, realize that you may not be able to be a seafood restaurant, but you can be in the restaurant business. The business must make a profit and every cost must be accounted.

Fifth, serve what sells. Menu design and layout is important; however, knowing what the market in the immediate vicinity of the restaurant's location wants is paramount. As mentioned in the previous paragraph, ethnic restauranteurs must serve what sells. Unlike chains that have the ability to carry those stores placed in areas that struggle from time to time due to location, changes in the economy, etc., the small operator does not have this support system. When considering that an operator must employ the fifth driver, serve what sells, may challenge the first driver, which is staying true to the culture of the ethnic restaurant. In the United States, ethnic restaurants are often Americanized to attract enough of an audience to stay in business. Many Asian and Mexican restaurants face this challenge. Menu items that are used in the traditional dishes may be too foreign to wide audience, and thus, adaptations must be made.

The goal to keep in mind is to make a profit while giving the customer an authentic experience. Authenticity can be communicated in many ways that honor the goal such as hiring servers and cooks of the ethnicity of the restaurant, decorating with authentic appointments, serving food in the style of the indigenous culture, and playing music that is common to restaurants that reside in the cultural location of the theme represented. Foods such as blowfish, dog, hakarl (fermented basking shark, popular in Iceland), escamole (ant larvae, popular in Mexico), and kopi luwak (coffee beans defecated by Civets, small animals found in southeast Asia) are examples of foods that are indigenous to a particular culture, but are not only difficult and expensive to 
obtain, but would likely not be ordered by the general dining public in the United States.

\section{Discussion}

As the ethnic population and thus, the number of ethnic restaurants continues to grow, the focus on what these operators and their employees need to better comply with food safety expectations is critical. Increased awareness of their cultures, behaviors expected of their cultures, preparation techniques that make their food unique yet possibly of danger to the public, and overall improved training programs that are written in their language are efforts that would improve the communication that preparing food in a safe manner and in a sanitary environment is an obligation to the public. Further, it is a requirement to maintain licensure, abiding by federal and state food safety mandates, and being an ethnical business owner. David Walczak (2000), Walczak, 2001; and Walczak \& Reuter (2002, 2004) and Knight et al (2009) refer to the failure of management to institute proper food safety procedures in place as 'corporate violence', respectively, and further communicate that overcoming the barriers to food safety is critical to lowering medical costs in the United States and loss of businesses important to the over health of a nation's tourism industry (Walczak, 1997, 1999).

Immigrant business in the United States faces a myriad of challenges. Despite the growing populations of certain ethnic groups, most restaurants representing ethnicities different from traditional American restaurants, fit the traditional ethnic profile of being small, independent, sparsely staffed, English language deficient, and limited in service. The uniqueness, however, of the ethnic restaurant offers an experience that is difficult to duplicate by the competition. Ethnic restaurants are on the rise and with the dining public eating out more than ever before, independent restaurants are becoming a part of the travel destination decision as well as desirable amenities in cities of all sizes. The challenges of maintaining sales that cover expenses yet yield a profit, maintaining qualified staff, having staff that speak the indigenous language of the locals in addition to their cultural language, and cooperating with local licensing agencies to meet operating compliance expectations. Ethnic restaurants have a higher closure rate in their struggle to compete with larger chains, and due to the issues mentioned, delivering a consistent product at an affordable price requires the institution of the five success drivers previously mentioned.

\section{References}

Abidin, U. F. U. Z., Arendt, S. W., \&Strohbehn, C. H. (2013). Exploring the culture of food safety: The role of organizational influencers in motivating employees' safe food-handling practices. Journal of Quality Assurance in Hospitality \& Tourism, $14,321-343$. 
Bennet, M. J. (1986). A developmental approach to training for intercultural sensitivity. International Journal of Intercultural Relations, 10, 179-196.

Berry, L. (1999). The soul of service. New York, New York: The Free Press.

Byrd-Bredbenner, C., Berning, J., Martin-Biggers, J. \& Quick, V. (2013). Food safety in home kitchens: A synthesis of the literature. International Journal of Environmental Research and Public Health, 10, 4060-4085.

Cho, S., Hertzman, J., Erdem, M., \&Garriott, P. O. (2013). A food safety belief model for Latino (a) employees in foodservice. Journal of Hospitality Research, 37(3), 330-348.

Fabiano, Karen. Coming to the United States: The Importance of Food for Preserving Italian and Slovak Ethnic Identity. n.d. 22 November 2014. <http://www.miseri cordia.edu/honorus/KFabianoPaper.cfm>.

Jang, S., Liu, Y., \&Namkung, Y. (2011). Effects of authentic atmospherics in ethnic restaurants: Investigating Chinese restaurants. International Journal of Hospitality Management, 23(5), 662-680.

Jevsnik, M. Hlebec, V., \& Raspor, P. (2008). Food safety knowledge and practices among food handlers in Slovenia. Food Control, 19(12), 1107-1118.

Harris, K. J., Murphy, K. S., DiPietro, R. B., \& Rivera, G. L. (2015). Food safety inspection results: A comparison of ethnic-operated restaurants to non-ethnic operated restaurants. International Journal of Hospitality Management, 46, 190199.

Kang, H. J., Lee, M. W., Hwang, I. K., \& Kim, J. W. (2015). Development of safe food handling guidelines for Korean consumers. Journal of Food Protection, 78(8), 1541-1546.

Khoury, H. A. (2006). Measuring culture: The development of a multidimensional culture scale. Graduate Theses and Dissertations, University of South Florida Scholar Commons. http://scholarcommons.usf.edu/etd/2584, pp. 1-80.

Leffel, T. (2016). Eat where the locals eat. Abroad.com, http://www.transitionsabroad. com/publications/magazine/0405/eat_where_locals_eat.shtml. Accessed September 7, 2016.

Liu, P. \& Kwon, J. (2013). The exploration of effects on Chinese cultural values on the attitudes and behaviors of Chinese restaurateurs toward food safety. Journal of Environmental Health, 75(10), 38-46.

Medeiros, C. O., Cavalli, S. B., Proenca, R. P. C. (2012). Human resources administration processes in commercial restaurants and food safety: The actions of administrators. International Journal of Hospitality Management, 31, 667674.

Parsa, H. G., van der Rest, Jean-Pierre I, Smith, S. R., Parsa, R. A., \&Bujisic, M. (2015). Why restaurants fail? Part IV: The relationship between restaurant failures and demographic factors. Cornell Hospitality Quarterly, 56(1), 80-90.

Peterson, B. (2004). Cultural Intelligence: A Guide to Working with People from Other Cultures. Intercultural Press: Yarmouth, Maine.

Pfeffer, J. (1998). Seven practices of successful organizations. California Management Review, 40(2), 96-124.

Powell, D. A., Jacob. C. J., \& Chapman, B. J. (2011). Enhancing food safety culture to reduce rates of foodborne illness. Food Control, 22, 817-822.

Quested, T. E., Cook, P. E., Gorris, L. G., \& Cole, M. B., (2010). Rends in technology, trade, and consumption likely to impact on microbial food safety. International Journal of Food Microbiol, 139, S29-S42. 
Ram, M., Abbas, T., Sanghera, B., Barlow, G. \& Jones, T. (2013). Apprentice entrepreneurs? Ethnic minority workers in the independent restaurant sector. Work, Employment, \& Society, 15(2), 353-372.

Ram, M., Sanghera, B., Abbas, T. Barlow, G. \& Jones, T. (2000). Ethnic minority business in comparative perspective: The case of the independent restaurant sector. Journal of Ethnic and Migration Studies, 26(3), 495-510.

Roberts, K., Kwon, J., Shanklin, C., Liu, P., \& Yen, W. S. (2011). Food safety practices lacking in independent ethnic restaurants. Journal of Culinary Science \& Technology, 9, 1-16.

Ruiz, P., Ruiz, C., \& Martinez, R. (2010). Improving the "leader-follower" relationship: Top manager or Supervisor? The ethical leadership trickle-down effect on follower job response. Journal of business ethics, DOI 10.1007/s10551101-0670-3.

Support of Diet Education Act (2009). http://elaw.klri.re.kr/eng_mobile/viewer.do? hseq=29018\&type=part\&key=36, accessed September 15, 2016.

Walczak, D. \& Reuter, M. (2002). Relationships: Food safety and organizational behavior. The FIU Hospitality Review, 20(1), 42-50.

Walczak, D. \& Reuter, M. (2004). Putting restaurant customers at risk: Unsafe food handling as corporate violence. International Journal of Hospitality Management, 23, 3-13.

Walczak, D. (1997). The sanitation imperative. Cornell Hotel and Restaurant Administration Quarterly, 38(2), 68-73.

Walczak, D. (1999). Organizational behavior: Forgotten variable in safe food. The FIU Hospitality Review, 17(1), Article 3, 21-27.

Walczak, D. (2000). Overcoming barriers to restaurant food safety. The FIU Hospitality Review, 18(2), Article 8, 89-97.

Walczak, D. (2001). Food safety in restaurants: A human relations model. The FIU Hospitality Review, 19(1), 26-36.

Yoo, T. (2015). Country of origin and diners' perceptions of a cuisine: The moderating effects of culinary and institutional factors. Journal of Hospitality \& Tourism Research, 20, 125-135. 